\title{
The Sequential Composition of Collaborative Groups' Emotion Regulation in Negative Socio-emotional Interactions
}

\author{
Kristiina Mänty $^{1}$ (D) Hanna Järvenoja ${ }^{1}$ (D) $\cdot$ Tiina Törmänen $^{1}$ (D)
}

Received: 24 June 2021 / Revised: 26 October 2021 / Accepted: 23 November 2021 /

Published online: 18 January 2022

(C) The Author(s) 2022

\begin{abstract}
Research indicates that to adjust a group's emotional atmosphere for successful collaborative learning, group members need to engage in group-level emotion regulation. However, less is known about the whys and ways regulation is activated at a group level. This research explores what triggers 12-year-old primary school students' $(\mathrm{N}=37)$ negative socio-emotional interactions during a collaborative science task and whether the nature of the trigger makes a difference to group-level emotion regulation strategies and their sequential composition in these interactions. Groups' collaborative working was videotaped, and triggers and strategies were analysed. The results reveal that the triggers of negative interactions are linked to the groups' activated regulation strategies. Motivation control strategies were more represented in situations where negative interactions were triggered by task-related issues, whereas socially related triggers were associated with behavioural regulation strategies. Furthermore, the results illustrate that strategies are concatenated to a series of strategic actions, which mostly begin with sharing an awareness of the trigger. The results indicate a need to focus on the series of strategic actions activated in group interactions. This will help reveal how socially shared regulatory processes build a group's emotional atmosphere.
\end{abstract}

Keywords: Collaborative learning · Socio-emotional interaction · Emotion regulation · Emotion regulation strategy

\section{Introduction}

Classroom learning forms a socio-emotional environment where learning is embedded in social relationships and interactions (Pekrun \& Linnenbrink-Garcia, 2012). Compared with individual-centred approaches, collaborative learning places an even greater emphasis on

Kristiina Mänty

kristiina.manty@oulu.fi

1 Learning and Educational Technology Research Unit, Faculty of Education, Department of Educational Sciences and Teacher Education, Learning and Educational Technology Research Unit, University of Oulu, PO Box 2000, FIN-90014 Oulu, Finland 
socio-emotional interactions because collaborative learning relies on shared expertise and learning together. In collaborative learning, students are expected to build a shared understanding by verifying and negotiating their individual views (Barron, 2003; Dillenbourg, 1999; Stahl et al., 2006). This inevitably creates cognitive, socio-emotional and motivational challenges that, if not managed appropriately, may hinder productive learning, hence creating negative learning experiences for learners (Van den Bossche et al., 2006; Andriessen et al., 2013; Lobczowski, 2020).

In collaborative learning, socio-emotional interactions co-occur and are intertwined with cognitive and task-related interactions (Isohätälä, Näykki \& Järvelä, 2020a). In these interactions, group members can share and shape their perceptions of emotions and the socio-emotional climate of the group (Bakhtiar, Webster \& Hadwin, 2018; Rogat \& Adams-Wiggins, 2015; Kreijns, Kirschner \& Jochems, 2003) while reviewing the collaborative learning process and issues related to it (Isohätälä et al., 2020a; Kreijns et al., 2003; Bakhtiar et al., 2018). At best, socio-emotional interactions enable a group to build a joint understanding of the conditions for learning together and, in this way, help make accurate interpretations of the situation to manage group learning and functioning, when needed (Törmänen et al., 2021a, b; Ucan \& Webb, 2015; Lajoie \& Lu, 2012).

Successful collaborative learning rests on the ability to recognise the instances in socioemotional interactions in which individual- and group-level emotion regulation is required (Mänty et al., 2020; Lobczowski, 2020), along with the capacity to engage in appropriate regulation to overcome or prevent potential escalations of conflicts (Engelschalk, Steuel \& Dresel, 2017). However, research indicates that group members do not always correctly interpret situations where emotions are triggered by different factors (Järvenoja \& Järvelä, 2013), nor do group members jointly take charge of regulatory activities to manage the situation at hand (Järvelä et al., 2013). As essential as individual-level emotion regulation is, engaging merely in regulating one's own emotions in collaborative learning situations has limited effects on group functioning. Without considering the group-level outcomes, mere individual level regulation can even lead to disfunction within the group (Näykki et al., 2014; Sommet et al., 2014). By engaging in group-level emotion regulation, groups can share their views and emotional experiences and this way, more accurately focus their regulation on maintaining, modifying and changing the course of socio-emotional interactions and group members' emotional and motivational states to better fuel the learning process (Lobczowski, 2020; Järvenoja \& Järvelä, 2013).

However, some previous research results suggest that even when groups engage in group-level emotion regulation, groups' regulatory attempts do not necessarily succeed in changing the course of the interactions, nor do they affect individual students' emotional experiences. This indicates that the chosen regulation strategies may not always be sufficient for the specific situation (Mänty et al., 2020; Näykki et al., 2014). To understand why and how collaborative groups activate group-level emotion regulation to manage socio-emotional interactions, we need a more fine-grained understanding of what triggers these interactions and how they are related to the emotion regulation the groups engage in. The current research focuses on these aspects by specifically exploring negative socioemotional interactions, because previous research shows that negative socio-emotional interactions often challenge a group's learning process (Rogat \& Adams-Wiggins, 2015). More precisely, the focus of the present research is on exploring the triggers of negative socio-emotional interactions and group-level use of emotion regulation strategies in these interactions. Another focus is on the quality of these strategic activities and the sequential composition of strategy use that occurs during the interactions. To ground this aim with prior research, we next discuss negative socio-emotional interactions in collaborative 
learning. We elaborate on what triggers negative interactions and how they are manifested at both the individual and group levels, along with how groups can deal with socio-emotional experiences by engaging in emotion regulation.

\section{What triggers negative socio-emotional interactions in collaborative learning?}

Earlier research has identified various challenges in group learning situations that may create negative socio-emotional interactions (Järvenoja \& Järvelä, 2009; Kurki et al., 2014; Näykki et al., 2014). These challenges may have origins in individual-level issues, such as low self-esteem (Ng \& Lee, 2015), self-efficacy (Zeidner, 2014; Pekrun \& LinnenbrinkGarcia, 2012) or interest in the topic (Mänty et al., 2020; Shubina et al., 2021). They can also emerge from individual attitudes towards group work in general (Kreijns \& Kirschner, 2018; Hammar Chiriac, 2014) or the attributions of that specific group process (Koivuniemi, Järvenoja \& Järvelä, 2018). Through socio-emotional interactions, these individual starting points can manifest as motivational issues in task engagement (Blumenfeld et al., 2006) or negative emotional reactions (Zschocke et al., 2016; Mänty et al., 2020) and redirect the course of collaborative learning (Linnenbrink-Garcia et al., 2011; Sinha et al., 2015). However, the collaborative learning situation itself can also act as the source and context of the emotional reactions of individuals (Isohätälä et al., 2018; Rogat \& AdamsWiggins, 2015). At the group level, previous research has identified issues in collaborative working that may arise from negative socio-emotional interactions: these can be, for example, issues in task work or task characteristics (Zschocke et al., 2016) or discrepancies related to task engagement (Blumenfeld et al., 2006). They can also be, for example, issues in communication (Arvaja et al., 2007; Khosa \& Volet, 2014) or in interpersonal relationships between the group members (Bourner, Hughes \& Bourner, 2001; Barron, 2003; Zschocke et al., 2016). Whatever the trigger for negative socio-emotional interactions may be, they have the potential of unleashing emotions among group members, which means that the group's attention will be required to solve these issues (Hadwin et al., 2018).

Even though these interactions may challenge the group's functioning, they can also act as mediums for bringing out individual negative experiences, which the group must then manage. Sharing emotions and experiences with the group and solving socio-emotional issues together by engaging in group-level emotion regulation may help group members manage their emotions (Rimé, 2007). This can help the group create a socio-emotional atmosphere where it is easier to provide new ideas and elaborate on learning results more effectively (Andriessen et al., 2013; Järvenoja et al., 2013).

\section{Strategies to regulate emotions in interactions}

On an individual level, emotion regulation in a learning context manifests as attempts to monitor, evaluate, and change one's own emotions - their intensity, duration and the type of emotion experienced-to ensure the effort and completion of academic tasks (Wolters, 2003; Boekaerts \& Pekrun, 2015). However, when emotion regulation is brought to the group level, it becomes a social process. In group learning, regulatory activities are directed either at other group members to manage their own emotions (self-regulation) or 
at others' emotions and the group's socio-emotional interactions (co-regulation), or they are shared with the group as a whole (socially shared regulation; Lobczowski, 2020; Järvenoja et al., 2013; Hadwin et al., 2018).

Earlier research has identified different regulation strategies that learners use to regulate their emotions (Wolters, 2003; Boekaerts \& Pekrun, 2015). Some of these strategies have also been applied to group learning situations (Näykki et al., 2014; Bakhtiar et al., 2018; Järvelä \& Järvenoja, 2011; Järvenoja et al., 2019). Here, regulation can be targeted at the situation or emotion itself: strategies targeted at the situation can include controlling the task conditions, group members' task enactment (Corno \& Kanfer, 1993; Järvenoja et al., 2019; Gross, 2014; Wolters, 2003) or the group's attention towards the task (Näykki et al., 2014; Gross, 2014). Strategies that aim at directly influencing the motivational and emotional aspects of the situation (Corno \& Kanfer, 1993; Järvenoja et al., 2019), in turn, include attempts to increase one's interest in the topic (interest enhancement; Wolters, 2003) or manage the attributions of one's own performance or attitudes towards the task (cognitive change; Gross, 2014; Wolters, 2003). Furthermore, strategies focused on motivational and emotional aspects can include attempts to modify emotional responses either by intentionally exaggerating, inhibiting or changing emotional reactions or expressions (response modulation; Gross, 2014). Attempts to maintain a positive atmosphere by joking or complimenting others have been identified as a more social way of managing emotions in group learning situations (social reinforcement; Järvelä \& Järvenoja, 2011).

So far, the theoretical understanding of emotion regulation strategies has been drawn from self-regulation research (e.g. Gross, 2014; Wolters, 2003), and there is little research on emotion regulation strategies at the group level. The scarce research on emotion regulation in groups has shown that some of the strategies that have been researched at the individual level may be modified for investigating group-level regulation processes as well (Kwon, Liu \& Johnson, 2014; Näykki et al., 2014; Lobczowski et al., 2021). For example, Lobczowski et al.'s (2021) recent work shows how socio-emotional regulation strategies in collaborative working can include behavioural, interpersonal, cognitive and motivational strategies that are activated both on the individual and group levels. In their study of pharmacy students, venting/complaining, showing empathy and reframing were commonly used group level regulation strategies (Lobczowski et al., 2021). It is likely that emotion regulation emerging as a shared attempt between group members differs from individual emotion regulation in that it is built up through interactions with the (shared) aim of affecting the socio-emotional grounds of a group's learning and collaboration. The ways strategies are applied at the group level can greatly vary, which makes it essential to further investigate the occurrence of these strategies and their relation to the challenges groups encounter (Kwon et al., 2014).

Research exploring how emotion regulation strategies are connected to the triggers causing the need to regulate, especially in group interactions, is basically non-existent. In Lobczowski's (2020) theoretical work, however, an attempt is made to profoundly connect the stimuli events in collaborative learning to the formation of students' emotions and their choice of emotion regulation strategies. Making this connection is essential in establishing whether strategies are relevant and effective (e.g., Davis \& Levine, 2013). Groups' ability to identify what triggers emotions among group members and activate appropriate regulatory strategies affects the direction of the whole social learning process and individual experiences (Näykki et al., 2014; Isohätälä et al., 2020b). Therefore, the current study aims to tackle these aspects of interactions by connecting the triggers of negative interactions to the ways group-level emotion regulation strategies are activated and linked in negative socio-emotional interactions. 


\section{Aim of the study}

The present research aims to explore how groups engage in strategic activities to regulate emotions in negative socio-emotional interactions during collaborative learning tasks, along with how these strategic activities are related to the triggers of these interactions. The research questions are as follows:

1. What triggers negative socio-emotional interactions in collaborative learning?

2. How do group members engage in regulating negative socio-emotional interactions with different types of triggers?

3. How are group-level regulation strategies organised in negative socio-emotional interactions with different types of triggers?

3.1 How many strategies do the groups engage in when regulating negative interactions?

3.2 How are different strategies positioned in negative interactions in relation to other strategic activities?

3.3 What kinds of combinations of strategies do the groups engage in when they regulate negative interactions?

\section{Methodology}

\section{Participants and context}

The participants were sixth-grade (approximately 12-year-old) students from one primary school in Finland. Altogether, 37 students $(17 \mathrm{M}, 20 \mathrm{~F})$ participated. The students were assigned to gender heterogeneous groups. Eleven groups had three members, and one group had four. Group formation was based on their task interest in science learning, as assessed by the Task Interest Inventory (Cleary, 2006). The groups were formed so that students were heterogeneous in terms of their task interest. This way, the groups were similar to each other in terms of task interest differences within the group. This resulted in the formation of 12 groups in total.

The groups were working in a classroom-like learning and research space and were asked to carry out a collaborative task related to science during their school day. Three groups were present in the learning and research space at a time. This group work was recorded using $360^{\circ}$ cameras. Overall, 18 hours of video data were gathered from the groups' collaborative activities. Informed consent for participating was requested from the participants and their parents. Furthermore, ethics approval was given by the University's Ethics Committee. The names of the participants are replaced with pseudonyms to ensure the participants' anonymity. The metadata with information of the collaborative task are provided in the dataset (Järvenoja et al., 2021)".

\section{Collaborative task}

The task dealt with designing and constructing a model of an energy-efficient house that makes use of solar energy. Students could use different materials (e.g., cardboard, tape, aluminium foil, cotton wool, Styrofoam sheets) to build the house and had to adhere to certain rules. 
Before the building task, the teacher presented basic information about heat energy in a 10-minute presentation. After this, the task consisted of four different phases: 1) becoming an expert (15 $\mathrm{min}), 2)$ brainstorming (10 $\mathrm{min}), 3)$ sketching (20 $\mathrm{min})$ and 4) building (60 $\min$ ). Every phase was timed, and the time remaining was visible throughout the task. In the first phase, each individual student received information about one specific area related to heat energy and the building of houses. The subtopics assigned to the group members were heat capacity of different materials, heat conduction, and heat convection. Students had 15 minutes to read the material and make notes about their own subtopics. After that, students started to work collaboratively in groups. In phase two, they were instructed to share their expertise and brainstorm a list of things to keep in mind while sketching and building the house. After brainstorming, the students started phase three, in which they made a sketch of and designed a floor plan for their house. The instructions stated that the sketch should demonstrate how the house should be built and which materials should be used. The last phase was the actual building of the house.

\section{Analysis}

\section{Detecting socio-emotional interactions from video data}

Video data were analysed by first detecting episodes of negative socio-emotional interactions (Table 1) during the group task (Kreijns et al., 2003; Bakhtiar et al., 2018; Törmänen et al., 2021a, b). Overall, 422 episodes of negative interactions were detected. These interactions were the source of data for uncovering the triggers and emotion regulation strategies. Negative socio-emotional interactions were defined as interactions that started with a negative comment (e.g., 'We are idiots', 'We are running out of time!') and/or a nonverbal expression of negative emotion (e.g., shouting, sighing) from at least one group member, followed by a reaction from another group member (see the examples in Tables 2 and 3). The unit of analysis was a meaningful episode that lasted for as long as the socio-emotional interaction between the group members continued. The end of one socio-emotional interaction was coded when the interaction related to the issue ended; this happened when the issue was solved or the discussion about it ended or changed to something else. Interrater reliability coding was carried out for $30 \%$ of the video data by another researcher. The interrater reliability was explored by using Cohen's Kappa statistics. For identifying socioemotional interactions $(\kappa=0.693)$ and defining the valence of interactions $(\kappa=0.723)$, substantial agreement was reached.

Table 1 Descriptive of the variables of negative socio-emotional interactions and regulated negative interactions.

\begin{tabular}{llrrrr}
\hline Interaction episodes & Group $N$ & Min. & Max. & M & SD \\
\hline Regulated negative interactions $(\% *)$ & 12 & 16 & 58 & 32.61 & 12.308 \\
Negative interaction (seconds) & 12 & 302 & 2085 & 1130.39 & 611.503 \\
\hline
\end{tabular}

*The percentual amount of negative interactions which contained regulation 
Table 2 Examples of negative interactions with a social trigger.

\begin{tabular}{|c|c|}
\hline Social trigger & Examples \\
\hline $\begin{array}{l}\text { Issues with participation in the task, off-task-related } \\
\text { behaviour, teasing }\end{array}$ & $\begin{array}{l}\text { 'I don't think I am useful for this task', Maria says, } \\
\text { after jokingly making 'silly' suggestions for the } \\
\text { task. Niilo responds, 'No, Kaisa is more useful; } \\
\text { you are causing more harm'. } \\
\text { 'We are constantly mean to Kalle', Juho says and } \\
\text { laughs a bit. }\end{array}$ \\
\hline Social issues related to the task conduct & $\begin{array}{l}\text { 'Don't touch my masterpiece', Niilo says to Maria } \\
\text { when she tries to do something to their house. } \\
\text { 'Come on, it's our house, too, not just yours', Maria } \\
\text { responds, and Kaisa agrees with her. }\end{array}$ \\
\hline Issues with working as a group & $\begin{array}{l}\text { 'Nobody listens to my suggestions', Kalle says. } \\
\text { 'You have made so many bad suggestions, we can't } \\
\text { trust you anymore', Milla responds. }\end{array}$ \\
\hline
\end{tabular}

Table 3 Examples of negative interactions with indications of a task-related trigger.

\begin{tabular}{ll}
\hline Task-related trigger & Example \\
\hline Progress with or attitudes towards the task & $\begin{array}{c}\text { Nadia starts, 'I am so annoyed, I thought we had more time'. } \\
\text { Niko answers, 'Me too but ... we were all being slow'. }\end{array}$ \\
Mistakes or failures in task conduct & $\begin{array}{l}\text { We have forgotten to consider the doors and windows of the } \\
\text { house!' Nina points out, sounding worried. Niko answers, } \\
\text { 'Oh no', and they all laugh a bit. } \\
\text { Task understanding or task difficulty } \\
\text { 'I only understood one part of my material', Nadja says and } \\
\text { explains it. Another group member, Jaana, responds, 'I } \\
\text { didn't understand any of mine'. }\end{array}$ \\
\hline
\end{tabular}

\section{Identifying triggers of negative socio-emotional interactions from video data}

The analysis proceeded by identifying and categorising the different observable triggers of each negative socio-emotional interaction from the video data. The identification of the triggers was done by analysing each socio-emotional interaction episode and searching for indications, where the issue starting the negative interaction was either directly articulated or indirectly expressed by a group member. Regarding the unit of analysis, for each socioemotional interaction episode, one trigger was identified and coded. By using an inductive content analysis, the researcher looked for the similarities and differences between identified triggers. After rounds of exploring the similarities and differences of the triggers and looking for a more general common denominator for the triggers, two distinct categories were formed: task-related triggers and social triggers (Tables 2 and 3). Task-related triggers were related to any aspects of task execution that did not include issues related to other group members' behaviour or issues between the group members. These could be, for example, issues with managing time or mistakes, frustrations or failures in terms of task understanding or conduct. In addition, prior research has identified task difficulty, its characteristics or task management as the triggers of negative emotions in collaborative groups (Zscoke et al., 2016; Kazemitabar \& Lajoie, 2017). Interactions with a social trigger consisted of clear issues between the group members, such as when one group member 
considered another member's behaviour as unhelpful or inappropriate or when group members' off-task or other behaviour created a negative response from other group members. Earlier research has also found that group functioning can be challenged, for example, by distractions from group members' off-task behaviour, joking or negative social contributions (Heinimäki et al., 2021) or unevenly distributed task contributions among the group members (Kreijns et al., 2003). In the analysis, the interpretations made from the data were discussed with another researcher to ensure agreement. Finally, when the interrater reliability coding was carried out for $30 \%$ of the data with another researcher for the triggers, almost perfect agreement was reached $(\kappa=0.879)$.

\section{Identifying groups' regulation strategies in negative socio-emotional interactions}

Next, the group-level emotion regulation strategies were coded in chronological order. The unit of analysis was the initiation of a strategic activity by one group member during a negative interaction episode. Regulation was regarded as occurring at the group level when at least one group member expressed regulation attempts regarding the group task, other group members or the whole group and when another group member responded to this attempt. The coding of the qualities of regulation strategies was partly inductive. That is, no categories were set up prior to the coding, but the researcher compared the strategies identified in the interactions to the previous categorisation of emotion and motivation regulation strategies from the literature (Corno \& Kanfer, 1993; Wolters, 2003; Gross, 2014; Boekaerts \& Pekrun, 2015; Järvenoja et al., 2019) and formed the categories based on these comparisons.

Five different categories were formed, encompassing five different strategies. The specific descriptions of the strategies can be found in Appendix 1 but, briefly, are as follows: 1) Task control consisted of strategies that aimed at making changes or adjustments to the task conduct to manage the issue triggering the negative interactions. 2) Sharing awareness consisted of activities where group members brought up their viewpoints or issues verbally at the group level. 3) Motivation control included activities where the group members aimed at downplaying issues by using positive comments or encouraging other group members or the whole group, reappraising issues that arose during the task conduct or maintaining a positive atmosphere by joking. 4) Behaviour control consisted of strategies that could affect other people's behaviour to manage the negative interaction. 5) Finally, communicating emotions consisted of strategies where group members intentionally communicated their emotions to other group members. The strategies were coded by two independent researchers. The disagreements between the two coders were discussed to reach a consensus for the codes in each category. The disagreements mainly dealt with how a certain category description was understood and how it manifested in the interaction; these

Table 4 Kappa values for strategies.

\begin{tabular}{lll}
\hline Strategy & Kappa value $(\kappa)$ & Agreement \\
\hline Task control & .895 & Almost perfect \\
Sharing awareness & .900 & Almost perfect \\
Motivation control & .893 & Almost perfect \\
Behaviour control & .723 & Substantial \\
Communicating emotions & .815 & Almost perfect \\
\hline
\end{tabular}


disagreements were solved by discussing and specifying the category descriptions. After the discussion, interrater reliability coding was conducted for $30 \%$ of the data. Cohen's kappa statistics were used to calculate the interrater reliability (see Table 4).

\section{Analysis of the triggers and strategies}

After locating the triggers of negative socio-emotional interactions and observable regulation strategies related to the same episodes, the analysis proceeded to investigate their co-occurrence. First, the number of times a strategy was used in the interactions was calculated. Second, how often a certain strategy was applied in differently triggered negative interactions was counted. A cross-tabulation of strategies and interaction triggers was created, and significant associations between strategies and the two types of triggers were examined by exploring significant $\mathrm{z}$ scores from the adjusted residuals with alpha levels of $.05(z>1.96)$ and $.001(z>2.58)$. The adjusted residuals showed whether a particular strategy occurred significantly more often in one of the conditions in terms of the triggers of negative interactions (Bakeman \& Quera, 1995).

After this, to understand how emotion regulation strategies were used as shared activities during negative socio-emotional interactions, the temporal concatenation of the strategic activities was analysed. First, how many strategies the group members activated during the same interaction sequence was investigated based on the same intervals (complexity of strategic activities, RQ 3.1). Second, how often each strategy was placed prior, in the middle or after other strategies in the temporal sequence was explored (positions of strategies, RQ 3.2). Third, the most likely combinations of strategies occurring together were also analysed (combinations of strategies, RQ 3.3). A seven-second interval was chosen for the time lag between the strategies, which was decided based on reviewing the data of different verbal and behavioural exchanges in interactions from the present video data and other video data of interactions (e.g., Kurki et al., 2017). This was identified as a short enough sequence to show strategies that were likely related to one another. Comparisons between those interactions with a social or a task-related trigger were made in terms of all the aspects of strategic activities. Significant associations of all the conditions were tested using the $\mathrm{z}$ scores from the adjusted residuals with alpha levels of $.05(z>1.96)$ and $.001(z$ $>2.58$ ) when possible. When this was not possible, a chi-square test (Bakeman \& Quera, 1995) was used to explore the associations of the conditions for specific variables.

\section{Results}

\section{RQ1. What triggers negative socio-emotional interactions in collaborative learning?}

The results show that the triggers for negative socio-emotional interactions in the collaborative groups emerged equally from both task-related triggers $(f=220, \mathbf{M}=18.3, \mathrm{SD}=$ $12.9)$ and social triggers $(f=202, \mathrm{M}=16.8, \mathrm{SD}=16.1)$, here based on all the groups' data. However, the amounts of each trigger varied a lot between the groups. Task-related triggers included, for example, issues with managing time, progress of the task or mistakes, frustrations or failures in terms of task understanding or conduct (see the examples in Table 3). 


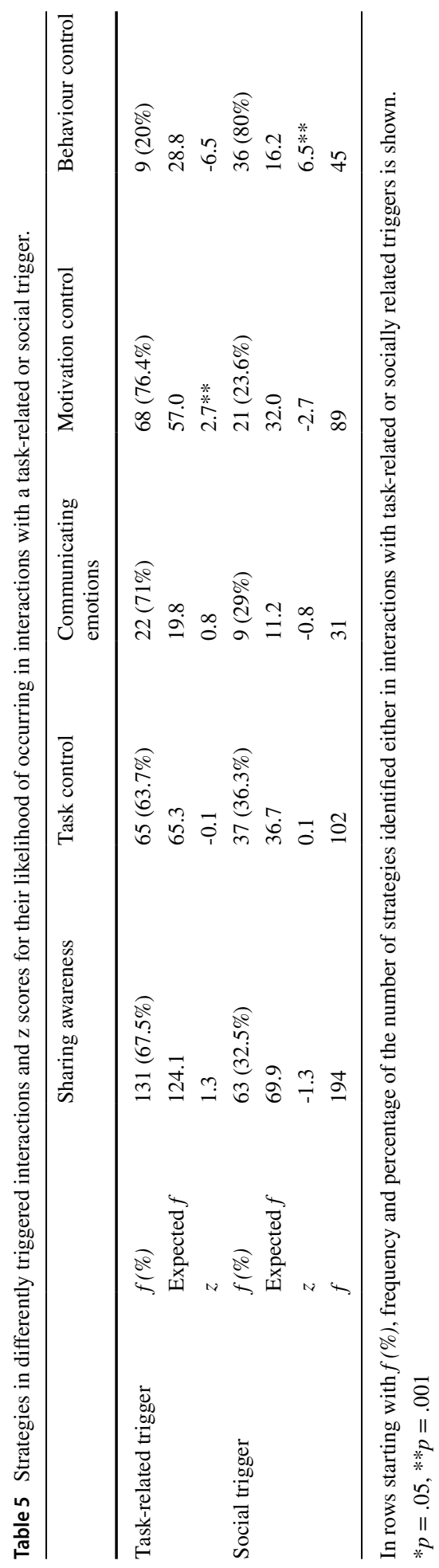


Interactions with a social trigger could be related to participation or the lack of participation in the task, one group member disturbing the others' task progress, off-task behaviour, ignoring of group members' ideas or other issues in group functioning (see the examples in Table 2).

$R Q 2$. Do group members engage in the regulation of negative socio-emotional interactions with different types of triggers?

Group members used five distinct strategies to regulate emotions in negative interactions. The most used strategy for regulating negative socio-emotional interactions was sharing awareness $(f=194)$, followed by task control $(f=102)$ and motivation control $(f$ = 89) (see Appendix 1 for the strategy descriptions). The least common strategies were behaviour control $(f=45)$ and communicating emotions $(f=31)$. When exploring strategies in differently triggered interactions (Table 5), motivation control was activated significantly more often in interactions with a task-related trigger than in interactions with a social trigger $(f=68, \mathrm{z}=2.7)$. In turn, behaviour control was significantly more often activated in interactions with a social trigger $(f=36, \mathrm{z}=6.5)$, and it was the least common strategy used in the interactions with a task-related trigger $(f=9)$.

$R Q 3$. How are group-level regulation strategies organised in negative socio-emotional interactions with different types of triggers?

The ways in which the strategies were activated in differently triggered interactions were examined in three ways. First, using seven-second intervals, the analysis explored how many strategies were most commonly activated during the same negative interaction and, second, how the strategies were positioned in relation to other strategies. Third, the strategies that occurred the most often together and in which order were investigated.

\section{RQ3.1. How many strategies do the groups engage in when regulating negative interactions?}

When exploring how many strategies were activated in the same negative socio-emotional interactions, it was found that groups activated, at most, three different strategies during the same sequence of interactions (see the example in Table 7). Moreover, there were some differences between the differently triggered interactions in terms of how many strategies were activated (Table 6). Here, in interactions with a task-related trigger, the group members were significantly more likely to use a larger variety of

Table 6 Number of strategies activated together in interactions with a task-related or a social trigger.

\begin{tabular}{lllll}
\hline & & \multicolumn{3}{l}{ Number of strategies } \\
\hline \multirow{2}{*}{ Task-related trigger } & $f$ & 1 & 2 & 3 \\
& Expected $f$ & 130.6 & 63.1 & 12.3 \\
& $\%$ & $58.7 \%$ & $32.0 \%$ & $9.2 \%$ \\
Social trigger & $z$ & -2.2 & 0.7 & $3.2 * *$ \\
& $f$ & 92 & 37 & 1 \\
& Expected $f$ & 82.4 & 39.9 & 7.7 \\
& $\%$ & $70.8 \%$ & $28.5 \%$ & $0.8 \%$ \\
& $z$ & $2.2 *$ & -0.7 & -3.2 \\
& In all & 213 & 103 & 20 \\
\hline
\end{tabular}

$* p=.05, * * p=.001$ 
Table 7 Strategic activities during a task-related negative socio-emotional interaction using three different strategies.

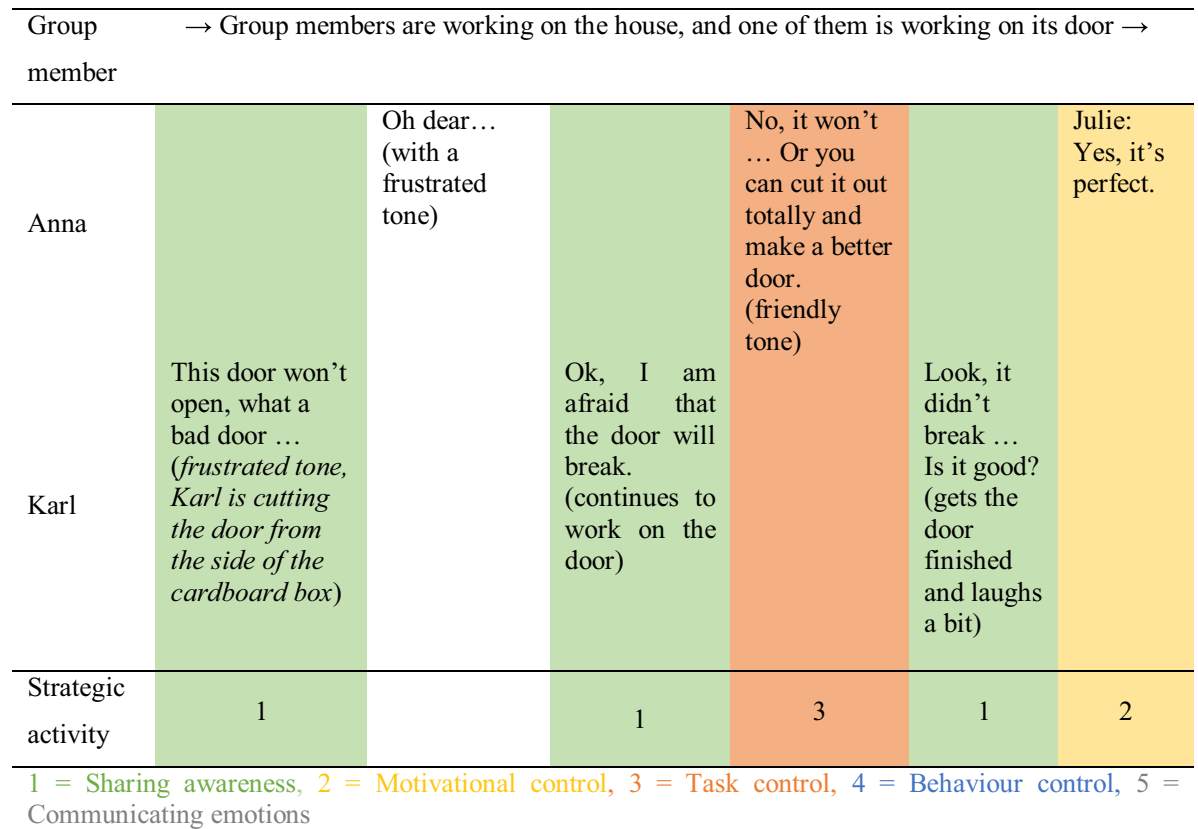

Table 8 Strategic activities during a socially related negative socio-emotional interaction using three different strategies.

\begin{tabular}{|c|c|c|c|c|c|}
\hline $\begin{array}{l}\text { Group } \\
\text { member }\end{array}$ & \multicolumn{5}{|c|}{$\begin{array}{l}\rightarrow \text { The group is working on their house and have a disagreement about what each of the } \\
\text { should be doing } \rightarrow\end{array}$} \\
\hline Arttu & & Who? What? & 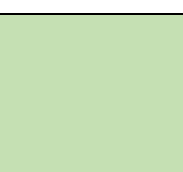 & $\begin{array}{l}\text { I just got it! } \\
\text { Don't take it } \\
\text { now, I am doing } \\
\text { this ... } \\
\text { (frustrated tone) }\end{array}$ & \\
\hline Lena & $\begin{array}{l}\text { You had it all the } \\
\text { time!! (yells with a } \\
\text { frustrated tone) }\end{array}$ & & $\begin{array}{l}\text { That piece of } \\
\text { cardboard (still } \\
\text { yelling) }\end{array}$ & & $\begin{array}{l}\text { I will make } \\
\text { the wall } \\
\text { now, so you } \\
\text { go and do } \\
\text { something } \\
\text { else. Go and } \\
\text { hang } \\
\text { wallpaper or } \\
\text { something. } \\
\text { (impatient } \\
\text { tone) }\end{array}$ \\
\hline $\begin{array}{l}\text { Strategic } \\
\text { activity }\end{array}$ & 1 & & 1 & 4 & 3 \\
\hline
\end{tabular}


strategies: three strategies were used in $9 \%$ of the interactions $(z=3.2)$ when compared with interactions with a social trigger $(0.8 \%)$. Moreover, in interactions with a social trigger, only one type of strategy was significantly more likely to be activated $(71 \%, z=$ 2.2) compared with those interactions with a task-related trigger.

The examples in Tables 7 and 8 show how several strategies were activated and positioned during the same interactions. In Example 2, the group used three different strategies during the interaction, which was triggered by a task-related reason: an issue with the door. Karl first brought the problem to the group's attention (sharing awareness), which made Anna sigh and respond to Karl's frustration by suggesting a solution if the previous attempt were to fail (task control). As a result, the problem was solved and acknowledged (sharing awareness) by Karl, who also sought confirmation of its success by asking for Anna's feedback. Anna replied by complimenting Karl's work (motivation control).

$R Q$ 3.2. How are different strategies positioned in the negative interactions in relation to other strategic activities?

The results show that the strategy of sharing awareness was significantly more often initiated than other strategies $(f=83, z=6.9)$, whereas motivation control $(f=46, z$ $=5.7$. $)$ and task control $(f=39, z=2.7)$ were more likely to follow other strategies (Appendix 2). When comparing the strategy positions in differently triggered interactions, in socially triggered interactions (Chart 1), the strategies occurred somewhat more often one at a time $(f=92,55.4 \%)$ when compared with in task-triggered interactions $(f$ $=121,41 \%),(\chi 2(1)=9.972, f=464, p<.05, V=.15)$. When looking at each strategy separately, this was the case for all strategies save for task control, which occurred alone nearly as often in interactions with a task-related trigger $(f=30,46.2 \%)$ as in those with a social one $(f=18,48.6 \%)$. In terms of the initiating strategies, in interactions with a task-related trigger, sharing awareness more often initiated the other strategies $(f=64$, $48.9 \%)$ than in interactions with a social trigger $(f=19,31.2 \%)$, and in both cases, it

\section{Positions of strategies in interactions with task or socially related triggers}

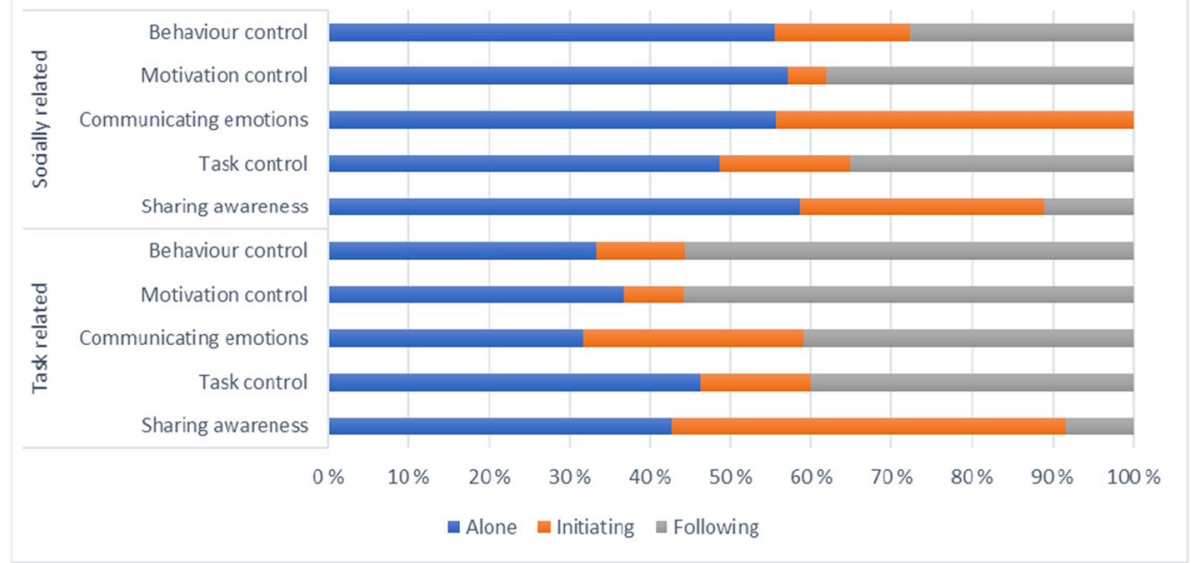

Chart 1 Positions of the strategies in seven-second intervals in interactions with a task- or social related trigger 
was the least likely to follow other strategies. Also, in terms of the strategy concerning communicating emotions, we can see a clear difference between the two trigger conditions, but the frequency of this strategy was low. The examples of how the positions of the strategies appeared during the interactions are demonstrated in Tables 7, 8 and 10.

\section{RQ3.3. What combinations of strategies do the groups engage in when regulating negative interactions?}

The most common combinations of strategies in the seven-second intervals (Table 9) were pairs of sharing awareness-motivation control (overall $f=33$, task related $f=25$, socially related $f=8$ ) and sharing awareness-controlling the task (overall $f=30$, task related $f=$ 19 , socially related $f=11$ ). Examples of these pairs are presented in Table 9 to illustrate how these strategies were used together.

Strategy combinations including three or more different strategies were less common; they were found in 17 sequences of strategies. The most common combination was sharing awareness-task control-motivation control $(f=7)$, and the second most common was sharing awareness-task control-behaviour control $(f=4)$. Combinations with three or more different strategies were almost always found in interactions with a task-related trigger. Only one (communicating emotions-sharing awareness-task control) was found in a socially triggered interaction. This indicates that social triggers were managed using combinations of fewer different strategies.

Sharing awareness-motivation control (example in Table 10). When exploring how group members used the strategy of sharing awareness followed by motivation control, they most often raised a problem with the task conduct or its outcome or with social issues at the group level (sharing awareness). However, the group members apparently did not see a need for change in terms of task conduct because they were more likely to downplay the issue by boosting positive emotions and their own confidence as a group (motivation control) by stating that they were doing well, joking about problems, or comparing their work to other groups in a positive way.

Sharing awareness-task control (example in Table 10). In situations where group members activated strategies of sharing awareness followed by task control, a group member pointed out an issue at the group level, either related to task conduct or interpersonal issues, leading to attempts to solve the issue by looking for solutions to fix it, for example, by sharing the tasks differently or making changes to them.

Table 9 The most common combinations of strategies in chronological order using two or three different strategies.

\begin{tabular}{llllll}
\hline Strategy & $\begin{array}{l}\text { Task- } \\
\text { related } \\
\text { trigger }\end{array}$ & $\%$ & $\begin{array}{l}\text { Social- } \\
\text { related } \\
\text { trigger }\end{array}$ & $\%$ & Overall \\
\hline Sharing awareness-motivation control & 25 & 75.8 & 8 & 24.2 & 33 \\
Sharing awareness-task control & 19 & 63.3 & 11 & 36.7 & 30 \\
Sharing awareness-task control-motivation control & 7 & 100 & 0 & 0 & 7 \\
Sharing awareness-task control-behaviour control & 4 & 100 & 0 & 0 & 4 \\
In all & 55 & & 19 & & 74 \\
\hline
\end{tabular}


Table 10

\begin{tabular}{ll}
\hline Strategy combinations & Examples \\
\hline $\begin{array}{l}\text { Sharing awareness-motivation control } \\
\text { (Task-related trigger) }\end{array}$ & $\begin{array}{l}\text { Look what those others are doing! They started } \\
\text { using that (a cardboard box)! (disappointed tone) } \\
\text { Yes, but they don't have as pretty a house as ours }\end{array}$ \\
\hline $\begin{array}{l}\text { Sharing awareness-task control } \\
\text { (Social trigger) }\end{array}$ & $\begin{array}{l}\text { You are preventing us from participating ... We } \\
\text { are giving you choices, but you reject our ideas all } \\
\text { the time. (frustrated tone) } \\
\text { Well, you can plan then. Please. (offers pen and } \\
\text { paper to others) }\end{array}$ \\
\hline $\begin{array}{l}1=\text { Sharing awareness, } 2=\text { Motivational control, } 3=\text { Task control, } 4=\text { Behaviour control, } 5= \\
\text { Communicating emotions }\end{array}$ &
\end{tabular}

\section{Discussion}

There is little previous empirical research exploring the strategic activities in group-level emotion regulation during collaborative learning (Mänty et al., 2020; Järvenoja et al., 2021). However, there is a vast amount of research covering individual-level emotion regulation strategies in general (e.g., Gross, 2014) and in a learning context (Wolters, 2003; Boekaerts \& Pekrun, 2015). Recent theoretical advancements on emotion generation and regulation processes also consider the factors affecting the formation and regulation of emotions in a collaborative setting; they illustrate the complex nature of the group-level process of emotion regulation in learning situations (Lobczowski, 2020; Järvenoja \& Järvelä, 2013; Bakhtiar \& Hadwin, 2020). The present research has empirically showcased these complex relations by investigating what triggers negative interactions and what kinds of emotion regulation strategies are activated at a group level to address these interactions, as well as by describing how regulation manifests in these interactions as a series of strategies.

The results show that groups' interactions were triggered by both task- and social-related issues. These results are in line with Lobczowski's (2020) socio-emotional formation and regulation model, in which emotion formation in collaborative learning is described as stimulated by task-related, non-task-related and social-related factors. The results also resonate with earlier studies finding both task-related and social reasons for negative socioemotional interactions or for the negative emotions of individuals in collaborative learning situations (e.g. Kazemitabar \& Lajoie, 2017; Heinimäki et al., 2021). In the present study, the groups activated group-level emotion regulation by using five distinctive strategies. The strategies found in group interactions can be somewhat traced back to individual types of regulation strategies (e.g., Wolters, 2003; Gross, 2014). Compared with the negative interactions with task-related triggers, in socially triggered negative interactions, the groups more often engaged in simple strategic attempts to control others' behaviour to manage the issues between group members (behaviour control; Kurki et al., 2017; Rogat \& AdamsWiggins, 2015). In turn, in those interactions triggered by task-related issues, the groups used a wider variety of different strategies; they engaged more in reappraising the mistakes or issues in the task process in a positive light, as well as maintaining a good atmosphere (motivation control; Corno \& Kanfer, 1993; Rogat \& Adams-Wiggins, 2015). This resonates with Splichal et al.'s (2018) study, which shows that groups are less likely to activate 
socially shared regulation when they face social issues among group members when compared with issues dealing with task conduct.

Even though group-level emotion regulation strategies have similarities with individuallevel emotion regulation strategies, group level strategies all have a social layer because they have been shared with others. Directing regulation at a group level can activate new strategic actions within the group to manage the issue at hand. Among regulated learning research, Zheng et al.'s (2019) study reveals that high-performing groups timed their socially shared monitoring activities more accurately, engaged more in shared regulatory activities and used a wider variety of regulation strategies than low-performing groups. Therefore, to improve the current understanding of group-level (co- and socially shared) regulation provided by previous theoretical and empirical work (Hadwin et al., 2018; Järvenoja \& Järvelä, 2013; Bakhtiar \& Hadwin, 2020), the current study suggests that strategic activities in emotion regulation should be looked at as a series of actions. As the research exploring regulated learning in collaborative activities has noted, not only do the qualities of strategic actions matter, but also the order in which they are activated and how they are flexibly altered according to situation-specific needs (Greene \& Azevedo, 2007; Winne, 2014).

The results of the present study show that the groups tended to start their strategic activities by sharing awareness of the issue at hand, which includes similarities with metacognitive monitoring in self-regulated learning research (Winne \& Hadwin, 2008). The results imply that sharing awareness provides an opportunity for other group members to engage in strategic emotion regulation when negative interactions emerge. In both task and socially triggered situations, where more than one strategy was activated, this mainly began with the strategy of sharing awareness, followed by task or motivation control. This is logical for group-level emotion regulation because by its very definition, it requires sharing an awareness of the regulation need with group members (Hadwin et al., 2018). For example, Lajoie and Lu (2012) showcase how prompts for metacognitive monitoring in collaborative learning could lead to co-regulation activities and, further, to more efficient task management. It can be assumed that similar to the notion from self-regulated learning theories, where metacognitive monitoring is considered essential for cognitive control to occur (Winne \& Hadwin, 2008), sharing awareness (i.e., making monitoring visible to others) can also act as a determinant for the accurate choice and activation of group-level emotion regulation strategies.

Most of the research on emotion regulation carried out at the individual level has relied on self-reported, retrospective or manipulated strategy use, where it is relatively easy to isolate different strategies from each other (e.g. Bebko et al., 2014; Cole et al., 2009; Davis \& Levine, 2013). These studies have provided information, for example, about children's subjective understanding of emotion regulation strategies or the effectiveness of instructed strategy use when learning. However, group-level process data from an authentic setting can show how regulation activities can be connected to each other and to the context more profoundly (Vauras \& Volet, 2013; Boekaerts \& Pekrun, 2015). Based on current research, we argue that a more fine-grained analysis of the qualities of activated strategies can increase the understanding of how they direct a group to manage issues in the learning process because it is not necessarily only about the 'right' strategy, but also about how it is used and brought to the group's attention (Hadwin \& Winne, 2012; Kwon et al., 2014). Furthermore, there is a need to further explore how the emotion regulation strategies that have been developed for self-regulation can be transferred to or altered for the group level because by 
its very nature, group-level regulation is a distinct process from self-regulation (Hadwin et al., 2018).

As for the limitations of the current study, the data analysis was based on video data of the group process. Thus, the interpretations of the interactions were made by the researchers, without information about the underlying triggers causing the negative interactions that were not expressed in the interactions or the rationale behind the choice of strategies used by the participants. For understanding, for example, the intentionality of strategic activities and the underlying causes of negative interactions, an additional, subjective data collection method, such as stimulated recall interviews, could complement the analysis (Järvenoja et al., 2018). Furthermore, because the present study's focus was on group-level triggers and strategies, the detailed reactions of individuals were not explored. Understanding how individuals participate in socio-emotional interactions and in regulating those interactions, a more detailed approach is needed. This has been done in Törmänen et al.'s (2021a, b) study, which shows that individuals who initiated regulation behaviour were often also the ones experiencing the issue that needed regulating. Because video analysis is time-consuming, the sample size was kept relatively small in the present study. The amount of data was further restricted by the fact that socio-emotional interactions that are followed by regulation attempts that aim to control them occur relatively rarely (see, e.g., Järvenoja et al., 2019; Mänty et al., 2020). A larger sample size would provide more possibilities for applying statistical analyses and for the verification of the findings. Furthermore, even though this analysis has made contributions in terms of understanding emotion regulation at the group level, the strategic activities were still analysed as individually activated actions. There is a need to increase the understanding of the shared regulation process as an entity where each participating group member plays their part in shared attempts to maintain or change the course of the interactions. And finally, this study did not analyse the effects of the triggers and strategies to the overall success of the group learning. To understand what makes strategy use successful, there is a need for further exploration of how the strategic activities used in collaboration are reflected in the product of collaboration or the overall satisfaction of the group members (Bakhtiar et al., 2018; Koivuniemi et al., 2018).

To conclude, the current study has contributed to the literature on emotion regulation by investigating how group members activate strategies to overcome negative interactions emerging during collaborative learning. Understanding group-level emotion regulation processes in detail is essential because it is evident that the quality of the interactions groups engage in and their ability to regulate their interactions in a way that keeps their focus on the task and prevents negative feelings concerning social relations makes a difference to their success in both collaboration and learning (Barron, 2003; Kwon et al., 2014; Andriessen et al., 2013; Isohätälä et al., 2020b; Näykki et al., 2014). This highlights a need for appropriate pedagogical approaches that can help children in acquiring the skills to identify and manage socio-emotional interactions in group processes as a part of collaborative learning skills (Tolmie et al., 2010; Kurki et al., 2017). Furthermore, the current study sheds light on how regulation in groups happens during the coordinated interactions between group members. This highlights the need to go beyond research on individual strategies to describe emotion regulation strategies that are socially constructed.

Supplementary Information The online version contains supplementary material available at https://doi. org/10.1007/s10212-021-00589-3.

Acknowledgements This research was funded by the Academy of Finland (Grant number 297686) and Finnish Cultural Foundation (00200762) and carried out with the support of LeaF Research Infrastructure, University of Oulu, Finland. 
Funding Open Access funding provided by University of Oulu including Oulu University Hospital.

Open Access This article is licensed under a Creative Commons Attribution 4.0 International License, which permits use, sharing, adaptation, distribution and reproduction in any medium or format, as long as you give appropriate credit to the original author(s) and the source, provide a link to the Creative Commons licence, and indicate if changes were made. The images or other third party material in this article are included in the article's Creative Commons licence, unless indicated otherwise in a credit line to the material. If material is not included in the article's Creative Commons licence and your intended use is not permitted by statutory regulation or exceeds the permitted use, you will need to obtain permission directly from the copyright holder. To view a copy of this licence, visit http://creativecommons.org/licenses/by/4.0/.

\section{References}

Andriessen, J., Pardijs, M., \& Baker, M. J. (2013). Getting on and getting along: Tension in the development of collaboration. In Baker, M. J., Andriessen, J., \& Järvelä, S. (Eds.), Affective learning together: Social and emotional dimensions of collaborative learning (pp. 205-230). Routledge

Arvaja, M., Salovaara, H., Häkkinen, P., \& Järvelä, S. (2007). Combining individual and group-level perspectives for studying collaborative knowledge construction in context.. Learning and Instruction, 17(4), 448-459. https://doi.org/10.1016/j.learninstruc.2007.04.003

Bakeman, R., \& Quera, V. (1995). Log-linear approaches to lag-sequential analysis when consecutive codes may and cannot repeat. Psychological Bulletin, 118(2), 272-284. https://doi.org/10.1037/0033-2909. 118.2.272

Bakhtiar, A., \& Hadwin, A. (2020). Dynamic interplay between modes of regulation during motivationally challenging episodes in collaboration.. Frontline Learning Research, 8(2), 1-34. https://doi.org/ 10.14786/flr.v8i2.561

Bakhtiar, A., Webster, E., \& Hadwin, A. (2018). Regulation and socio-emotional interactions in a positive and a negative group climate. Metacognition and Learning, 13(1), 57-90. https://doi.org/10.1007/ s11409-017-9178-X

Barron, B. (2003). When smart groups fail. Journal of the Learning Sciences, 12(3), 307-359. https://doi. org/10.1207/S15327809JLS1203_1

Bebko, G. M., Franconeri, S. L., Ochsner, K. N., \& Chiao, J. Y. (2014). Attentional deployment is not necessary for successful emotion regulation via cognitive reappraisal or expressive suppression. Emotion (Washington, D.C.), 14(3), 504-512. https://doi.org/10.1037/a0035459

Blumenfeld, P. C., Kempler, T. M., \& Krajcik, J. S. (2006). Motivation and cognitive engagement in learning environments. In Sawyer, R. K. (Ed.), The Cambridge handbook of the learning sciences (pp. 475488). Cambridge University Press

Boekaerts, M., \& Pekrun, R. (2015). Emotions and emotion regulation in academic settings. In Corno, L., \& Anderman, E. M. (Eds.), Handbook of educational psychology (pp. 76-90). Routledge

Bourner, J., Hughes, M., \& Bourner, T. (2001). First-year undergraduate experiences of group project work. Assessment and Evaluation in Higher Education, 26(1), 19-39. https://doi.org/10.1080/0260293002 0022264

Cleary, T. J. (2006). The development and validation of the self-regulation strategy inventory-Self-report. Journal of School Psychology, 44(4), 307-322. https://doi.org/10.1016/j.jsp.2006.05.002

Cole, P. M., Dennis, T. A., Smith-Simon, K. E., \& Cohen, L. H. (2009). Preschoolers' emotion regulation strategy understanding: Relations with emotion socialization and child self-regulation. Social Development (Oxford, England), 18(2), 324-352. https://doi.org/10.1111/j.1467-9507.2008.00503.x

Corno, L., \& Kanfer, R. (1993). Chapter 7: The role of volition in learning and performance. Review of Research in Education, 19(1), 301-341. https://doi.org/10.3102/0091732X019001301

Davis, E. L., \& Levine, L. J. (2013). Emotion regulation strategies that promote learning: Reappraisal enhances children's memory for educational information. Child Development, 84(1), 361-374. https:// doi.org/10.1111/j.1467-8624.2012.01836.x

Dillenbourg, P. (1999). Introduction: What do you mean by collaborative learning? In Dillenbourg, P. (Ed.), Collaborative learning: Cognitive and computational approaches (pp. 1-19). Pergamon

Engelschalk, T., Steuer, G., \& Dresel, M. (2017). Quantity and quality of motivational regulation among university students. Educational Psychology, 37(9), 1154-1170. https://doi.org/10.1080/01443410. 2017.1322177 
Grau, V., \& Whitebread, D. (2012). Self and social regulation of learning during collaborative activities in the classroom: The interplay of individual and group cognition. Learning and Instruction, 22(6), 401-412. https://doi.org/10.1016/j.learninstruc.2012.03.003

Greene, J. A., \& Azevedo, R. (2007). Adolescents' use of self-regulatory processes and their relation to qualitative mental model shifts while using hypermedia. Journal of Educational Computing Research, 36(2), 125-148. https://doi.org/10.2190/G7M1-2734-3JRR-8033

Gross, J. J. (2014). Emotion regulation: Conceptual and empirical foundations. In Gross, J. J. (Ed.), Handbook of emotion regulation (pp. 3-20). The Guilford Press

Hadwin, A., \& Winne, P. (2012). Promoting learning skills in undergraduate students. In J. Kirby \& M. Lawson (Eds.), Enhancing the quality of learning: Dispositions, instruction, and learning processes (pp. 201-227). Cambridge University Press. https://doi.org/10.1017/CBO9781139048224.013

Hadwin, A., Järvelä, S., \& Miller, M. (2018). Self-regulation, co-regulation and shared regulation in collaborative learning environments. In Schunk, D., \& Greene, J. (Eds.), Handbook of self-regulation of learning and performance (pp. 83-106). Routledge

Hammar Chiriac, E. H. (2014). Group work as an incentive for learning-students' experiences of group work. Frontiers in Psychology, 5, 558. https://doi.org/10.3389/fpsyg.2014.00558

Heinimäki, O., Volet, S., Jones, C., Laakkonen, E., \& Vauras, M. (2021). Student participatory role profiles in collaborative science learning: Relation of within-group configurations of role profiles and achievement. Learning, Culture and Social Interaction, 30, 100539. https://doi.org/10.1016/j.lcsi.2021.100539

Hennessy, S., \& Murphy, P. (1999). The potential for collaborative problem solving in design and technology. International Journal of Technology and Design Education, 9, 1-36. https://doi.org/10.1023/A: 1008855526312

Isohätälä, J., Näykki, P., \& Järvelä, S. (2020a). Cognitive and socio-emotional interaction in collaborative learning: Exploring fluctuations in students' participation. Scandinavian Journal of Educational Research, 64(6), 831-851. https://doi.org/10.1080/00313831.2019.1623310

Isohätälä, J., Näykki, P., \& Järvelä, S. (2020b). Convergences of joint, positive interactions and regulation in collaborative learning. Small Group Research, 51(2), 229-264. https://doi.org/10.1177/1046496419 867760

Isohätälä, J., Näykki, P., Järvelä, S., \& Baker, M. J. (2018). Striking a balance: Socio-emotional processes during argumentation in collaborative learning interaction. Learning, Culture and Social Interaction, 16, 1-19. https://doi.org/10.1016/j.lcsi.2017.09.003

Järvenoja, H., \& Järvelä, S. (2009). Emotion control in collaborative learning situations: Do students regulate emotions evoked by social challenges. British Journal of Educational Psychology, 79(3), 463-481. https://doi.org/10.1348/000709909x402811

Järvelä, S. \& Järvenoja, H. (2011). Socially constructed self-regulated learning in collaborative learning groups. Teachers College Records, 113(2), 350-374.

Järvenoja, H., \& Järvelä, S. (2013). Regulating emotions together for motivated collaboration. In M. Baker, J. Andriessen \& S. Järvelä (Eds.), Affective learning together: Social and emotional dimensions of collaborative learning (pp. 162-181). London, UK: Routledge. https://doi.org/10.4324/9780203069684

Järvelä, S., Järvenoja, H. Malmberg, J. \& Hadwin, A. (2013) Exploring socially shared regulation in the context of collaboration. Journal of Cognitive Education and Psychology, 12(3). https://doi. org/10.1891/1945-8959.12.3.267

Järvenoja, H., Järvelä, S., Törmänen, T., Näykki, P., Malmberg, J., Kurki, K., Mykkänen, A., \& Isohätälä, J. (2018). Capturing motivation and emotion regulation during a learning process. Frontline Learning Research, 6(3), 85-104. https://doi.org/10.14786/flr.v6i3.369

Järvenoja, H., Näykki, P., \& Törmänen, T. (2019). Emotional regulation in collaborative learning: When do higher education students activate group level regulation in the face of challenges? Studies in Higher Education, 44(10), 1747-1757. doi:10.1080/03075079.2019.1665318

Järvenoja, H., Mänty, K., \& Törmänen, T. (2021). EmReg - Emotion regulation in secondary school pupils' learning. Hanna Järvenoja. http://urn.fi/urn:nbn:fi:att:78e3a149-040f-49ff-8e1f-3b85dc10f230

Kazemitabar, M. A., \& Lajoie, S. P. (2017). Role of socio-emotional interactions on mutual trust and shared mental models in a case study of programming teams. International Society of the Learning Sciences

Khosa, D. K., \& Volet, S. E. (2014). Productive group engagement in cognitive activity and metacognitive regulation during collaborative learning: Can it explain differences in students' conceptual understanding? Metacognition and Learning, 9, 287-307. https://doi.org/10.1007/s11409-014-9117-z

Koivuniemi, M., Järvenoja, H., \& Järvelä, S. (2018). Teacher education students' strategic activities in challenging collaborative learning situations. Learning, Culture and Social Interaction, 19, 109-123. https://doi.org/10.1016/j.lcsi.2018.05.002

Kreijns, K., \& Kirschner, P. A. (2018). Extending the SIPS-model: A research framework for online collaborative learning. In V. Pammer-Schindler, M. Pérez-Sanagustín, H. Drachsler, R. Elferink, \& M. 
Scheffel (Eds.), Lifelong technology-enhanced learning. EC-TEL 2018. Lecture notes in computer science, 11082, 277-290). Springer. https://doi.org/10.1007/978-3-319-98572-5_21

Kreijns, K., Kirschner, P. A., \& Jochems, W. (2003). Identifying the pitfalls for social interaction in computer-supported collaborative learning environments: A review of the research. Computers in Human Behavior, 19(3), 335-353. https://doi.org/10.1016/S0747-5632(02)00057-2

Kurki, K., Järvelä, S., Mykkänen, A. \& Määttä, E. (2014). Investigating children's emotion regulation in socio-emotionally challenging classroom situations. Early Child Development and Care, 185(8): 12381254. https://doi.org/10.1080/03004430.2014.988710

Kurki, K., Järvenoja, H., Järvelä, S., \& Mykkänen, A. (2017). Young children's use of emotion and behaviour regulation strategies in socio-emotionally challenging day-care situations. Early Childhood Research Quarterly, 41(May), 50-62. https://doi.org/10.1016/j.ecresq.2017.06.002

Kwon, K., Liu, Y., \& Johnson, L. P. (2014). Group regulation and social-emotional interactions observed in computer supported collaborative learning: Comparison between good vs. poor collaborators. Computers and Education, 78, 185-200. https://doi.org/10.1016/j.compedu.2014.06.004

Lajoie, S. P., \& Lu, J. (2012). Supporting collaboration with technology: Does shared cognition lead to co-regulation in medicine? Metacognition and Learning, 7(1), 45-62. https://doi.org/10.1007/ s11409-011-9077-5

Linnenbrink-Garcia, L., Rogat, T. K., \& Koskey, K. L. K. (2011). Affect and engagement during small group instruction. Contemporary Educational Psychology, 36(1), 13-24. https://doi.org/10.1016/j. cedpsych.2010.09.001

Lobczowski, N. G. (2020). Bridging gaps and moving forward: Building a new model for socioemotional formation and regulation. Educational Psychologist, 55(2), 53-68. https://doi.org/10.1080/ 00461520.2019 .1670064

Lobczowski, N. G., Lyons, K., Greene, J. A., \& McLaughlin, J. E. (2021). Socioemotional regulation strategies in a project-based learning environment. Contemporary Educational Psychology, 65, 101968. https://doi.org/10.1016/j.cedpsych.2021.101968

Mänty, K., Järvenoja, H., Törmänen, T. \& Järvelä, S. (2020). Socio-emotional interaction in collaborative learning: Combining individual emotional experiences and group-level emotion regulation. International Journal of Educational Research, 102. https://doi.org/10.1016/j.ijer.2020.101589

$\mathrm{Ng}$, E., \& Lee, K. (2015). Effects of trait test anxiety and state anxiety on children's working memory task performance. Learning and Individual Differences, 40, 141-148. https://doi.org/10.1016/j.lindif.2015.04.007

Näykki, P., Järvelä, S., Kirschner, P. A., \& Järvenoja, H. (2014). Socio-emotional conflict in collaborative learning: A process-oriented case study in a higher education context. International Journal of Educational Research, 68, 1-14

Pekrun, R., \& Linnenbrink-Garcia, L. (2012). Academic emotions and student engagement. In Christenson, S. L., Reschly, A. L., \& Wylie, C. (Eds.), Handbook of research on student engagement (pp. 259-282). Springer

Rimé, B. (2007). Interpersonal emotion regulation. In Gross, J. J. (Ed.), Handbook of emotion regulation (pp. 466-487). Guilford

Rogat, T. K., \& Adams-Wiggins, K. (2015). Interrelation between regulatory and socioemotional processes within collaborative groups characterized by facilitative and directive other-regulation. Computers in Human Behavior, 52, 589-600. https://doi.org/10.1016/j.chb.2015.01.026

Shubina, T., Järvenoja, H., Mänty, K., Peltonen, J. \& Järvelä, S. (2021). The changes in lower secondary school students' interest during collaborative learning. Scandinavian Journal of Educational Research, 1-14. https://doi.org/00313831.2021.1958377

Sinha, S., Rogat, T. K., Adams-Wiggins, K., \& Hmelo-Silver, C. (2015). Collaborative group engagement in a computer-supported inquiry learning environment. International Journal of ComputerSupported Collaborative Learning, 10(3), 273-307. https://doi.org/10.1007/s11412-015-9218-y

Sommet, N., Darnon, C., Mugny, G., Quiamzade, A., Pulfrey, C., Dompnier, B., \& Butera, F. (2014). Performance goals in conflictual social interactions: Towards the distinction between two modes of relational conflict regulation. British Journal of Social Psychology, 53, 134-153. https://doi.org/10. 1111/bjso. 12015

Splichal, J. M., Oshima, J., \& Oshima, R. (2018). Regulation of collaboration in project-based learning mediated by CSCL scripting reflection. Computers and Education, 125, 132-145. https://doi.org/ 10.1016/j.compedu.2018.06.003

Stahl, G., Koschmann, T., \& Suthers, D. (2006). Computer-supported collaborative learning: An historical perspective. In Sawyer, R. K. (Ed.), Cambridge handbook of the learning sciences (pp. 409426). Cambridge University Press 
Tolmie, A. K., Topping, K. J., Christie, D., Donaldson, C., Howe, C., Jessiman, E. ... Thurston, A. (2010). Social effects of collaborative learning in primary schools. Learning and Instruction, 20(3), 177-191. https://doi.org/10.1016/j.learninstruc.2009.01.005

Törmänen, T., Järvenoja, H. \& Mänty, K. (2021a). Exploring groups' affective states during collaborative learning: what triggers activating affect on a group level? Educational Technology Research Development. 69, 2523-2545. https://doi.org/10.1007/s11423-021-10037-0

Törmänen, T., Järvenoja, H. \& Mänty, K. (2021b). All for one and one for all - How are students' affective states and group-level emotion regulation interconnected in collaborative learning? International Journal of Educational Research, 109. https://doi.org/10.1016/j.ijer.2021.101861

Ucan, S., \& Webb, M. (2015). Social regulation of learning during collaborative inquiry learning in science: How does it emerge and what are its functions? International Journal of Science Education, 37(15), 2503-2532. https://doi.org/10.1080/09500693.2015.1083634

Vauras, M., \& Volet, S. (2013). The study of interpersonal regulation in learning and its challenge to the research methodology. In Volet, S., \& Vauras, M. (Eds.), Interpersonal regulation of learning and motivation (pp. 1-13). Routledge

Van den Bossche, P., Gijselaers, W. H., Segers, M., \& Kirschner, P. A. (2006). Social and cognitive factors driving teamwork in collaborative learning environments: Team learning beliefs and behaviors. Small Group Research, 37(5), 490-521. https://doi.org/10.1177/1046496406292938

Winne, P. H. (2014). Issues in researching self-regulated learning as patterns of events. Metacognition and Learning, 9, 229-237. https://doi.org/10.1007/s11409-014-9113-3

Winne, P. H., \& Hadwin, A. F. (2008). The weave of motivation and self-regulated learning. In Schunk, D. H., \& Zimmerman, B. J. (Eds.), Motivation and self-regulated learning: Theory, research, and applications (pp. 297-314). Lawrence Erlbaum Associates Publishers

Wolters, C. A. (2003). Regulation of motivation: Evaluating an underemphasized aspect of self-regulated learning. Educational Psychologist, 38(4), 189-205. https://doi.org/10.1207/S15326985EP3804_1

Zeidner, M. (2014). Anxiety in education. In Pekrun, R., \& Linnenbrink-Garcia, L. (Eds.), International handbook of emotions in education (pp. 265-288). Routledge/Taylor \& Francis Group. https://doi.org/ $10.4324 / 9780203148211$

Zheng, J., Xing, W., \& Zhu, G. (2019). Examining sequential patterns of self- and socially shared regulation of STEM learning in a CSCL environment. Computers and Education, 136, 34-48. https://doi.org/10. 1016/j.compedu.2019.03.005

Zschocke, K., Wosnitza, M., \& Bürger, K. (2016). Emotions in group work: Insights from an appraisaloriented perspective. European Journal of Psychology of Education, 31(3), 359-384. https://doi.org/ 10.1007/s10212-015-0278-1

Publisher's Note Springer Nature remains neutral with regard to jurisdictional claims in published maps and institutional affiliations.

\section{Current themes of research:}

Corresponding authors' current themes of research are both in researching (1) emotional processes in collaborative learning settings among secondary school students (emotions, socio-emotional interactions, coand socially shared emotion regulation) and (2) early childhood education professionals' understanding and the use of co-regulation in supporting children's learning of emotion regulation skills.

\section{Most relevant publications in the field of Psychology of Education:}

Törmänen, T., Järvenoja, H., \& Mänty, K. (2021). All for one and one for all - how are students' affective states and group-level emotion regulation interconnected in collaborative learning? International Journal of Educational Research, 109, 101861. doi:https://doi.org/10.1016/j.ijer.2021.101861

Mänty née Kurki, K., Järvenoja, H., Törmänen, T. \& Järvelä, S. (2020). Socio-emotional interaction in collaborative learning: Combining individual emotional experiences and group-level emotion regulation. International Journal of Educational Research. 102. https://doi.org/10.1016/j.ijer.2020.101589

Järvenoja, H., Malmberg, J., Törmänen, T., Mänty née Kurki, K., Haataja, E., Ahola, S. \& Järvelä, S. (2020) Collaborative learning design for promoting and analysing adaptive motivation and emotion regulation in science classroom. Frontiers in Education, 5. https://doi.org/10.3389/feduc.2020.00111 
Kurki, K., Järvenoja, H. \& Järvelä, S. (2018). Exploring regulatory interactions among young children and their teachers: focus on teachers' monitoring. Journal of Early Childhood Education Research, 7(12), 310-337. https://jecer.org/exploring-regulatory-interactions-among-young-children-and-their-teachers-a-focus-onteachers-monitoring-activities/

Järvenoja, H., Järvelä, S., Törmänen, T., Näykki, P., Malmberg, J., Kurki, K., Mykkänen, A., \& Isohätälä, J. (2018). Capturing motivation and emotion regulation during a learning process. Frontline Learning Research, 6(3), 85 - 104. https://doi.org/10.14786/flr.v6i3.369

Kurki, K., Järvenoja, H., Järvelä, S., \& Mykkänen, A. (2017). Young children's use of emotion and behaviour regulation strategies in socio-emotionally challenging day-care situations. Early Childhood Research Quarterly, 41(May), 50-62. https://doi.org/10.1016/j.ecresq.2017.06.002

Kurki, K., Järvenoja, H., Järvelä, S., \& Mykkänen, A. (2016). How teachers co-regulate children's emotions and behaviour in socio-emotionally challenging situations in day-care settings. International Journal of Educational Research, 76, 76-88. https://doi.org/10.1016/j.ijer.2016.02.002 